\title{
Retraction notice to "Age-period-cohort analysis of female breast cancer mortality in Korea"
}

The editors, Breast Cancer

Published online: 12 June 2008

(C) The Japanese Breast Cancer Society 2008

Erratum to: Breast Cancer (2006) 13:266-271

DOI 10.2325/jbcs.13.266

The article "Age-period-cohort analysis of female breast cancer mortality in Korea" by Yunhee Choi, Yeonju Kim, Sue Kyung Park, Hai-Rim Shin and Keun-Young Yoo was published in Breast Cancer in 2006 (Vol. 13, No. 3, pp. 266-271, doi:10.2325/jbcs.13.266). Dr. Choi subsequently informed the editors of this journal that critical data in the article were not valid. Specifically, major errors were found in Table 2, which formed a key part of the article. Accordingly, the article is being editorially retracted, with an apology.

The online version of the original article can be found under doi:10.2325/jbcs.13.266.

The editors, Breast Cancer

The Japanese Breast Cancer Society, Tokyo, Japan

e-mail: bcan@springer.jp 